\title{
São Paulo Dialogue: Biodiversity, ecosystem services and human wellbeing - Matching capacity building needs with resources
}

\author{
Carlos Alfredo Joly ${ }^{1,2}$ \\ ${ }^{1}$ Universidade Estadual de Campinas, Instituto de Biologia, Departamento de Biologia Vegetal, \\ Campinas, SP, Brazil. \\ ${ }^{2}$ Corresponding author: Carlos Alfredo Joly,e-mail: cjoly@unicamp.br
}

1. The São Paulo Dialogue was an initiative of the IPBES Task Force on Capacity Building, planned by members of the task force and its Technical Support Unit and approved by the IPBES Bureau and Multidisciplinary Expert Panel (MEP) as an intersessional activity of IPBES. The dialogue was supported by the Governments of Norway and Brazil, and by State of São Paulo Research Foundation (FAPESP) through the BIOTA Program.

2. The objective of the dialogue was to provide advice on how IPBES might go about developing a "matchmaking facility" for bringing those who have capacity building needs (whether financial or technical) together with those who can help address those needs. Such advice will also be relevant in reporting to the third IPBES Plenary and in planning the IPBES Capacity Building Forum.

3. Participants, deliberately selected to cover a range of interests and sectors, were provided a discussion paper which set the essential context and provided some ideas for discussion. This was supplemented by inviting a number of participants to make brief presentations to "kick start" discussion.

4. Participants were encouraged to explore the matters in question from different angles and "think outside the box", helping to identify new approaches rather than repeating the same model unthinkingly. At the time several deliverables under the IPBES work programme were still in the early stages of implementation, and it was recognised that intergovernmental considerations on how these deliverables can best be achieved will benefit from deliberations such as the current dialogue.

\section{Context}

5. IPBES aims to strengthen the science policy interface for biodiversity and ecosystem services and thereby contribute to long term human wellbeing and sustainable development. An essential part of this will be sustainably building capacity at the science-policy interface.

6. One key challenge in building capacity is to find effective ways to sustainably address the current asymmetries in the ability to engage in science-policy interface processes such as assessment, development of policy support tools and knowledge generation.

7. In addressing capacity building it is important to reach out to different stakeholders across multiple sectors, in order to communicate to them how biodiversity and ecosystem services contribute to human wellbeing. However it is also important to establish a dialogue with those sectors whereby IPBES also can learn from their different experiences.

8. New institutional initiatives may be necessary, but improved networking and cooperation are essential to making the most effective use of what already exists. This may require investment, innovation, and exploration of how missions, objectives and business plans between potential partners best can be aligned.

\section{Learning from existing initiatives}

9. Matchmaking facilities of one form or another have been developed and implemented by a number of other organizations, and IPBES can learn from their experience. Activities undertaken by existing 'matchmaking' approaches include:

a) Creating and building partnerships between donors and those who have particular needs which require financial support.

b) Technical support and advice to help in development of proposals for funding, including helping to ensure it aligns with donor interests.

c) Helping to convene national recipient roundtable meetings to ensure alignment within the country before any proposal is taken to donors.

d) Helping to convene donor roundtables meetings to bring together those who have projects needing supporting, and existing and potential donors, including the necessary preparatory work.

e) Stimulating expression of interest submissions, aligned with national planning and relevant to the interests of the process sponsoring the matchmaking.

f) Advertise offers and opportunities for support online in areas such as volunteers, internships, training and partnerships.

g) Developing a cadre of ambassadors through engagement such as internships, training, presentations to students to spread knowledge about the tools and approaches available.

10. One additional point is that inviting providers to focus on a specific theme can directly and indirectly over time help raise the profile of the needs associated with the theme. This point may be considered as the Task Force prepares for the Capacity Building Forum. 
11. Challenges and lessons learned from existing matchmaking approaches related to the one IPBES is planning, indicate that an IPBES initiative should:

$\circ$ benefit from alignment with existing processes used by potential donors, providers and recipients

$\circ$ be designed so as not to raise expectations beyond the capacity to meet demands

$\circ$ consider the need for sustainability of funding for management and delivery

$\circ$ focus on technical and process needs, as well as on financial needs

- have a degree of active management, and not rely on an online clearing house alone

$\circ$ provide a means to bring people together both virtually and in reality

o address the fact that some potential recipients may need help in expressing their needs

$\circ$ be demand-driven, addressing the priority needs of experts, institutions, countries and regions

o embrace the need for careful planning based on identified needs and responses

o recognize that much can be done to develop/deliver capacity building through in kind support

o consider approaches that engage and involve the community

- recognize that language barriers exist

$\circ$ begin small and expand over time through an iterative and modular process

12. Gaining clarity on priority capacity building needs is essential and urgent. There are so many capacity building needs in the environment and development arena, and IPBES efforts risk being a failure unless the matchmaking facility focuses on the specific contribution that IPBES can and should make.

13. It is also essential that IPBES focuses on capacity building activities that respond to real demands and the challenges in meeting such demands. This may necessitate increased attention to understanding why some countries and/or organizations have not had their needs met in the past.
14. This will also include recognising and addressing needs relevant to (and focused on) specific regions and subregions, or even nations. May also need to recognise who the key actors are with respect to each of the different needs (which may also vary from one location to another).

15. One obvious lesson is that communication about the facility is essential in order to ensure awareness of what the facility is, where to find it, and what it can do for users. One way of doing this is through the IPBES National Focal Points, but it was noted that as of yet there is not an IPBES focal point in place in each country, nor terms of reference for such focal points.

16. However, additional communication through networks is essential rather than just communicating through national focal points. Reaching out through personal and professional networks of like-minded interest groups and individuals, including both national and regional networks, would spread the message and lead to involvement of many more people.

17. Part of the communication approach should be in convincing people that they are helping themselves by engaging with the matchmaking facility. This should be supported by follow up in order to pick up on those that do not respond the first time round.

18. Given the breadth of the existing landscape, and the range of different types of organizations with which IPBES could be working, and which could be brought together through matchmaking and other approaches, it is important to consider which specific types of institutions or processes should be prioritized, particularly at the start. This might include in the first instance:

o focusing on people and institutions that already have proven experience and know-how

$\circ$ encouraging south-south cooperation

$\circ$ promoting those public and private "centres of excellence" already working in this area

$\circ$ working with existing regional partnerships and networks

\section{IPBES Capacity Building Task Force}

